\title{
EPIDEMIOLOGY OF PHYSICAL ACTIVITY IN ADULT POLISH POPULATION IN THE SECOND DECADE OF THE 21ST CENTURY. RESULTS OF THE NATPOL 2011 STUDY
}

\section{WOJCIECH DRYGAS ${ }^{1,2}$, WOJCIECH SAKŁAK ${ }^{3}$, MAGDALENA KWAŚNIEWSKA ${ }^{1}$, PIOTR BANDOSZ ${ }^{4,5}$, MARCIN RUTKOWSKI ${ }^{4}$, WOJCIECH BIELECKI ${ }^{1}$, EWA RĘBOWSKA ${ }^{1}$, KATARZYNA PRUSIK ${ }^{3}$, and TOMASZ ZDROJEWSKI ${ }^{4}$}

${ }^{1}$ Medical University of Lodz, Łódź, Poland

Department of Preventive and Social Medicine

${ }^{2}$ Institute of Cardiology, Warszawa, Poland

Department of Epidemiology, Cardiovascular Disease Prevention and Health Promotion

${ }^{3}$ Gdansk University of Physical Education and Sport, Gdańsk, Poland

Department of Physical Education

${ }^{4}$ Medical University of Gdańsk, Poland

Department of Hypertension and Diabetology

${ }^{5}$ University of Liverpool, Liverpool, United Kingdom

Department of Public Health and Policy

\begin{abstract}
Objectives: The aim of the study was to assess physical activity (PA) level in a representative sample of Polish adults. Materials and Methods: A cross-sectional analysis was performed among 2413 randomly selected individuals $(51.5 \%$ women) aged 18-79 years, who participated in the Nationwide Study of Occurrence of Risk Factors of Cardiovascular Diseases NATPOL 2011 (March-July 2011). The study procedures consisted of a questionnaire as well as of anthropometric, blood pressure and biochemical measurements. Leisure-time, occupational and commuting PA were assessed by the use of a questionnaire interview. Results: About $48.2 \%$ of adults do exercise for at least 30 minutes on most days of a week. About $11 \%$ of the respondents declare a sedentary lifestyle. About $26.5 \%$ of working population report hard physical work, while sedentary work is reported by $47.6 \%$ of the employed participants. Active commuting is declared by $27.3 \%$ of working/studying population. About $47.2 \%, 36.6 \%$, and $15.3 \%$ spend $<15,15-30$, and $>30 \mathrm{~min}$ per day, respectively, on this kind of PA. Conclusions: PA level of more than half of Polish adults is still not satisfactory. Promotion of an active lifestyle should concern mainly leisure-time and commuting PA with paying special attention to substantial differences in various socio-demographic groups.
\end{abstract}

Key words:

Physical activity, Adult, Polish, Leisure-time, Occupational, Commuting

Received: February 2, 2013. Accepted: October 15, 2013.

Corresponding author: M. Kwaśniewska, Department of Preventive Medicine, Medical University of Lodz, Żeligowskiego 7/9, 90-752 Łódź, Poland (e-mail: magdalena.kwasniewska@umed.lodz.pl). 


\section{INTRODUCTION}

Data on substantial health benefits of an active lifestyle are thorough and robust. Since classic papers of Jerry Morris and colleagues indicating association between occupational physical activity (PA) and risk of coronary heart disease, numerous subsequent epidemiological studies have confirmed that regular exercise may prevent from chronic non-communicable diseases, improve well-being and considerably contribute to an increase in life expectancy [1-6]. More importantly, there is an increasing body of evidence that not only leisure-time, but also commuting activity connected with travelling to work or school may substantially modify the risk of cardiovascular and metabolic disorders [7-9].

According to the latest analysis based on model IMPACT published by Bandosz et al. (2012) over a half of the fall in the mortality due to coronary heart disease in Poland between 1991 and 2005 could be attributed to reductions of major risk factors [10]. An increase in leisure-time PA contributed to about $10 \%$ decrease in coronary death rate. The obtained results have clear implications for elaborating more effective strategies in health-related behaviours, including promotion of an active lifestyle. However, in spite of well documented favourable effects of PA, a significant proportion of European societies does not meet criteria for sufficient PA [11-14]. Apart from European region, long-term observation of lifestyle trends among the USA population revealed that the prevalence of regular PA decreased from $53 \%$ to $43 \%$ [15].

PA level in Poland has been monitored since late 90s. The most recent national cross-sectional study including comprehensive assessment of PA level was performed during the National Polish Multi-Center Health Survey (WOBASZ) in the years 2003-2005 [14]. Like other societies of Central and Eastern Europe, Poland is experiencing dynamic social, economic and epidemiological transition resulting in rapid and profound changes in individuals' lifestyles. Regular assessment of PA and monitoring trends across various population groups seem necessary in planning effective public health strategies.

The aim of the present study was to assess the level of current physical activity among Polish adults participating in a nation-wide representative sample of the NATPOL 2011 study. A special attention was paid to the socio-demographic determinants of PA level. The analysis was performed with regard to leisure-time physical activity (LTPA) as well as occupational and commuting PA. Findings of this study may substantially contribute to development of new national strategies in non-communicable diseases control and prevention in Poland.

\section{MATERIAL AND METHODS}

The Nationwide Study of Occurrence of Risk Factors of Cardiovascular Diseases NATPOL 2011 included a representative sample of 2413 (including 51.3\% of women) randomly selected Polish adults, aged 18-79 years. The sampling scheme had the following stratifications: firstly, 60 strata within the whole country were selected according to the type of area in each county using GUS TERYT database (types of areas: rural, small urban i.e < 50000 inhabitants, large urban areas, i.e. 50 000-200 000 inhabitants, and capital cities area, i.e. > 200000 inhabitants); secondly, samples of men and women aged 18-79 years were selected in each area based on the sex and age distribution within each strata and finally, the chosen sample was weighted so that its demographic distribution was proportional to that of the whole adult population of Poland.

The study was conducted by 240 specially trained nurses in 523 selected places located all over the country between March and July 2011. The initiative was prepared and realized by the Department of Hypertension and Diabetology of the Medical University of Gdańsk which cooperated with the Medical University of Warsaw and the Institute of Cardiology in Warsaw [15]. As the NATPOL sample was 
selected randomly from the entire GUS TERYT database, the participants of the study comprised both healthy persons as well as patients representing various health disorders and diseases. Socio-demographic characteristics of the NATPOL 2011 population are presented in Table 1.

The study procedure consisted of a survey questionnaire, anthropometric, biochemical and blood pressure measurements. The part of the questionnaire concerning socio-demographic and PA questions was comparable to that used in the previous population-based studies in Poland, like the Countrywide Integrated Non-communicable Diseases Intervention Program or WOBASZ Project $[14,16]$. In the survey questionnaire they analyzed 3 kinds of physical activity: LTPA, i.e. done in spare time; occupational PA, i.e. connected with doing professional work; commuting PA, i.e. travelling from home to work/school/university. In order to assess LTPA the respondents were asked the following questions: "Do you get involved in any continuous physical activity (jogging, cycling, swimming, doing gymnastics, gardening etc.) for at least 30 minutes?" (with 2 possible answers: "Yes" or "No") and "How often are you physically active (for at least 30 minutes)?" (with 6 answers possible, i.e. "every day", "almost every day", "every second or third day", "once a week", "twice or three times a month", "once a month or less").

In order to assess occupational PA the respondents were asked the following question: "What kind of work do you perform?" (with 3 answers possible: "strenuous and manual work i.e. you spend $50 \%$ of time doing hard work"; "sitting work, i.e. you spend more than $50 \%$ of time sitting or standing" or "different from the two mentioned above").

Due to concerns that appeared during realization of the previous national projects, questions regarding commuting habits in the NATPOL 2011 study were more detailed. In order to assess commuting PA the respondents were asked the following questions: "How do you get from home to work (school, university) and back?"

Table 1. Socio-demographic characteristics, by sex, of the study population of the NATPOL 2011 Study

\begin{tabular}{lcc}
\hline \multicolumn{1}{c}{ Characteristic } & $\begin{array}{c}\text { Women }(\mathrm{N}=1245) \\
\mathrm{n}(\%)\end{array}$ & $\begin{array}{c}\text { Men }(\mathrm{N}=1168) \\
\mathrm{n}(\%)\end{array}$ \\
\hline Age (years) & & \\
$18-39$ & $497(39.9)$ & $477(40.8)$ \\
$40-59$ & $405(32.5)$ & $444(38.0)$ \\
$60-79$ & $343(27.6)$ & $247(21.1)$ \\
Place of residence & & \\
rural/small towns & $496(39.8)$ & $617(52.8)$ \\
small urban areas & $422(33.9)$ & $347(29.7)$ \\
large urban areas & $327(26.3)$ & $204(17.5)$ \\
Educational level & & $551(47.2)$ \\
elementary & $405(32.5)$ & $617(52.8)$ \\
secondary or higher & $840(67.5)$ & \\
Marital status & & $297(25.5)$ \\
single & $290(23.3)$ & $784(67.2)$ \\
married & $646(51.9)$ & $33(2.8)$ \\
widowed & $197(15.8)$ & \\
\hline
\end{tabular}


(with 4 answers possible: "I use a car or a motorbike", "I use public transport", "I walk or ride a bike" or "I work or study at home"). Those who ticked active commuting were asked about time spent daily on walking/biking to or from work/school (with 4 answers possible: "less than 15 minutes", "between 15 and 30 minutes", "between 31 and 60 minutes", "more than 1 hour"). Additional question which was not included in WOBASZ questionnaire was addressed to those who do not walk or bike to/from work. These respondents were asked: "If you get from home to work (school, university) by car, motorbike or public transport do you also cover a short distance on foot, e.g. from a car park or a bus stop?" (with 2 answers possible: "Yes, I usually walk for at least 10 minutes" or "I usually walk for less than 10 minutes").

\section{STATISTICAL ANALYSIS}

SPSS 19 statistical package was used for statistical purposes. The results are presented in pivot tables and present data on a general number of respondents (with accuracy to 100 ) who have been classified in the particular category as well as the percentage distribution.

The calculations were made by the use of the stratified cluster sampling. To compare the frequency and to assess statistical significance of the given categories of quantitative characteristics in the analyzed groups, $\mathrm{Chi}^{2}$ test or $\mathrm{Chi}^{2}$ test with Yates' correction were implemented. We employed multivariate logistic regression analyses to explore factors that were associated with low LTPA (i.e. doing exercise twice a month or less). All p-values were two sided and a $p$-value $<0.05$ was considered statistically significant.

\section{RESULTS}

Distribution of leisure-time physical activity in the study population shows that almost half of the respondents (48.2\%) declare performing physical exercise for at least 30 minutes on most days of a week. Physical inactivity (i.e. doing exercises once a month or less) was found among $4.8 \%$ persons while $6.2 \%$ do exercise very seldom (i.e. 2-3 times a month). No significant differences were found between men and women regarding the time spent on LTPA (Table 2).

Of 1655 occupationally active persons, approximately $47.6 \%$ of them reported sitting work with significantly higher prevalence among women than men $(56.7 \%$ vs. $39.5 \%, p<0.001$ ) (Figure 1). Hard physical work was declared by about $19.2 \%$ of women and $32.9 \%$ of men $(\mathrm{p}<0.001)$.

The analysis of commuting PA confirmed that $18.1 \%$ of all the participants $(27.3 \%$ of the occupationally active population), significantly more often women than men ( $p<0.05)$, walk or cycle while travelling to work/school (Figure 2). Figure 3 shows the distribution of time spent on active

Table 2. Distribution of leisure-time physical activity in the study population, by sex

\begin{tabular}{lccc}
\hline \multicolumn{1}{c}{ Frequency of physical activity } & $\begin{array}{c}\text { Women } \\
(\%)\end{array}$ & $\begin{array}{c}\text { Men } \\
(\%)\end{array}$ & $\begin{array}{c}\text { Total } \\
(\%)\end{array}$ \\
\hline Every day & 33.8 & 36.9 & 35.4 \\
4-6 times a week & 13.2 & 12.4 & 12.8 \\
2-3 times a week & 23.1 & 24.0 & 23.6 \\
Once a week & 18.7 & 15.9 & 17.2 \\
2-3 times a month & 6.2 & 6.2 & 6.2 \\
Once a month or less & 5.0 & 4.6 & 4.8 \\
\hline
\end{tabular}




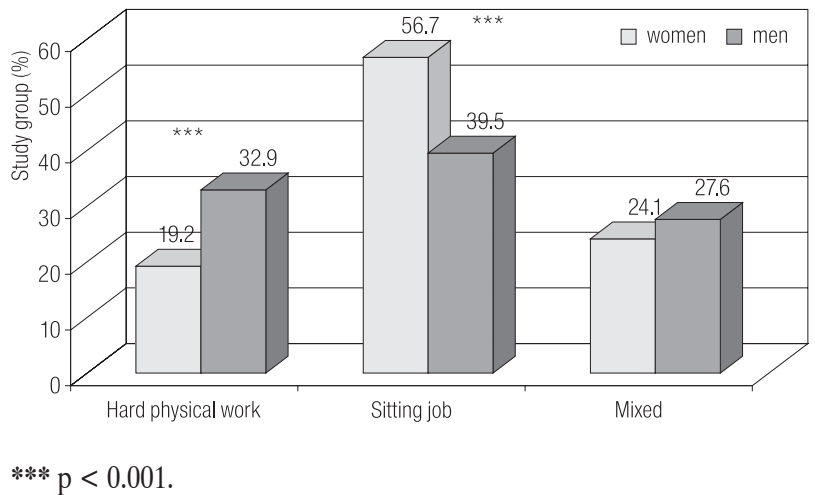

Fig. 1. Distribution of occupational physical activity in the study population, by sex

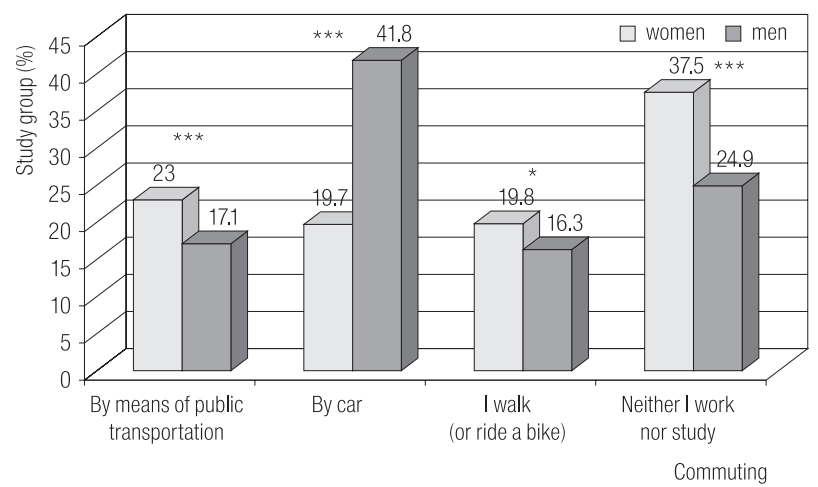

$* \mathrm{p}<0.05$

$* * * \mathrm{p}<0.001$

Fig. 2. Distribution of commuting physical activity in the study population, by sex

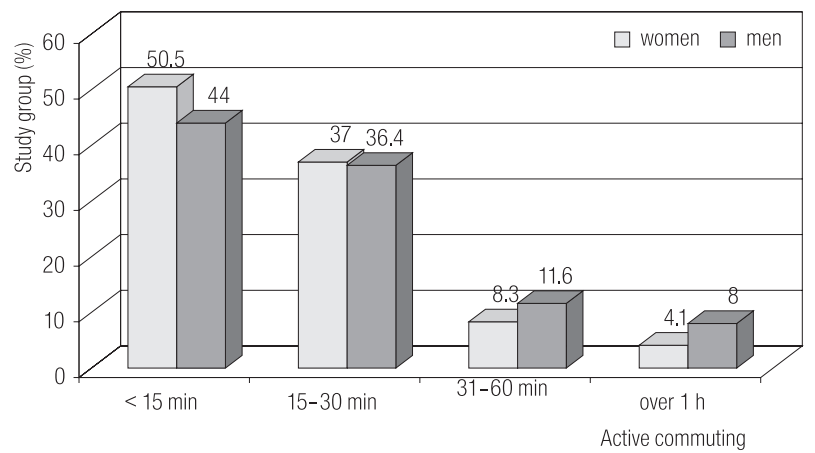

Fig. 3. Distribution of the time spent on active commuting ( $\mathrm{min} /$ day) in the study population, by sex

commuting. Almost half of the respondents who actively travel to work/school spend up to $15 \mathrm{~min}$ on this kind of PA. About $12.4 \%$ of women and $19.6 \%$ of men declare a high level of commuting PA, i.e. for more than 30 min per day. The results presented in Table 3 show the relationship between the socio-demographic and work-related factors and low LTPA level. Whereas in crude analyses several significant correlations were noted, after adjustment for possible confounders borderline differences remained only in the context of age and occupational PA. Likelihood of low LTPA was lower among men aged $<40$ years as compared to men aged $\geq 60$ years and higher among women declaring hard physical work as compared to those declaring sitting work.

Table 3. Low leisure time physical activity by socio-demographic and work-related physical activity characteristics in the NATPOL Study

\begin{tabular}{lcc}
\hline & \multicolumn{2}{c}{ OR $(95 \% \mathrm{CI})^{\mathrm{a}}$} \\
\cline { 2 - 3 } & men & women \\
\hline Age (years) & & $0.96(0.55-1.66)$ \\
$<40$ & $0.53(0.3-0.94)$ & $0.84(0.38-1.83)$ \\
$40-59$ & $0.49(0.23-1.04)$ & 1.00 \\
$\geq 60$ & 1.00 & 1.00 \\
Educational level & & $0.65(0.36-1.18)$ \\
elementary & 1.00 & \\
secondary/high & $0.77(0.47-1.26)$ & \\
\hline
\end{tabular}


Table 3. Low leisure time physical activity by socio-demographic and work-related physical activity characteristics in the NATPOL Study - cont.

\begin{tabular}{|c|c|c|}
\hline \multirow{2}{*}{ Characteristics } & \multicolumn{2}{|c|}{ OR $(95 \% \mathrm{CI})^{\mathrm{a}}$} \\
\hline & men & women \\
\hline \multicolumn{3}{|l|}{ Place of residence } \\
\hline rural/small urban & 1.00 & 1.00 \\
\hline large urban & $1.18(0.75-1.88)$ & $1.34(0.82-2.17)$ \\
\hline \multicolumn{3}{|l|}{ Marital status } \\
\hline single & 1.00 & 1.00 \\
\hline married & $1.11(0.66-1.89)$ & $0.58(0.34-1)$ \\
\hline divorced & $2.16(0.77-6.09)$ & $0.61(0.25-1.49)$ \\
\hline widowed & $0.45(0.02-8.09)$ & $0.53(0.19-1.46)$ \\
\hline \multicolumn{3}{|l|}{ Occupational physical activity } \\
\hline sitting work & 1.00 & 1.00 \\
\hline mixed work & $1.05(0.6-1.82)$ & $0.92(0.48-1.74)$ \\
\hline hard physical work & $0.63(0.34-1.16)$ & $1.40(1.02-1.72)$ \\
\hline \multicolumn{3}{|c|}{ Commuting physical activity (min/day) } \\
\hline 0 & 1.00 & 1.00 \\
\hline $1-15$ & $0.89(0.12-1.23)$ & $0.70(0.33-1.51)$ \\
\hline$\geq 15$ & $0.94(0.46-1.91)$ & $0.44(0.18-1.09)$ \\
\hline
\end{tabular}

OR - odds ratio; CI - confidence interval.

${ }^{a}$ Adjusted for age, place of residence, education, income, marital status and other forms of physical activity.

\section{DISCUSSION}

The presented results provide a comprehensive insight into the current leisure-time, occupational and commuting PA characteristics in Poland. According to the findings of the NATPOL 2011 study almost half of the Polish adult population (47\% of women and $49.3 \%$ of men) declare doing exercise continuously for minimum 30 min at least 4 times a week. Although almost one third of the respondents report rather low PA level (i.e. doing exercise once a week or less frequently), the percentage of physically active is generally higher than the one observed a few decades ago [16].

Public health recommendations suggest that at least $30-45 \mathrm{~min}$ of exercise of moderate-intensity 5 days weekly or $20 \mathrm{~min}$ of vigorous-intensity exercises 3 days weekly may provide substantial health benefits [17]. As intensity of exercises was not assessed during our study, it was not possible to calculate precisely the proportion of the individuals meeting the guidelines. However, the participants of the NATPOL study declaring doing exercise at least 120 min per week (including highintensity exercise) probably represent satisfactory LTPA level. Regarding the fact that commuting or occupational PA may be a possible alternative to LTPA in achieving health guidelines, analysis of other domains of activity was also performed in our sample. The obtained results show that about $75 \%$ of a working population has low or moderately active work and almost two thirds of men and more than $40 \%$ of women use a car or public transport to get to work or school.

As commuting PA was not significantly associated with LTPA, the individuals who spend more than 30 min per day on active transportation (12.4\% of women and $19.6 \%$ of men) may substantially enlarge the group of persons meeting the PA guidelines. 
Comparative studies conducted at the end of the 90s of the 20th century confirmed that Poland was among the least physically active societies in Europe. According to the results of the CINDI WHO Programme entitled "Bridging the East - West Health Gap", almost 70\% of the respondents living in big agglomerations declared a sedentary lifestyle. High PA level was declared only by $6.4 \%$ of Polish participants in the project while, for example, in Finland more than $30 \%$ of the respondents were involved in regular exercise most days per week [16]. Further observations performed during the NATPOL PLUS study showed that about $41 \%$ of women and more than $50 \%$ of men get involved in some physical activity in their leisure time. However, neither frequency nor duration of workout sessions were analyzed in this study, so direct comparisons with the present findings cannot be made [14].

The first comprehensive national analysis of various aspects of the lifestyle in Poland was conducted in the years 2003-2005 (WOBASZ Project 2003-2005) [18]. At that time the study group consisted of a randomly selected representative sample of 14769 Polish adults aged 20-74 years. The analysis of LTPA revealed that $39.5 \%$ of the respondents declared doing exercise for at least 30 minutes most days of a week and similar percentage was inactive (exercising once a month or less frequently). In the present study not only was the proportion of the most active individuals higher (48.2\%), but also the prevalence of physically inactive was markedly lower (4.8\%). The second edition of the WOBASZ project, which is currently being conducted, will reveal if this favourable trend in PA level in Poland is being continued.

In Europe, a sedentary lifestyle was more prevalent in Eastern and Southern parts of Europe, while a relatively low proportion of inactive persons was found among Northern societies (especially Scandinavian) [12]. Poland participated in several international comparative studies which provided inconsistent results. Findings of the European Health Interview Survey (EHIS, 2009) showed that every fourth Pole aged 15 or older does physical exercises every day [19]. According to the results of the Eurobarometer survey on sport and physical activity (2010), about $25 \%$ of adults in our country practise sports at least once a week and $60 \%$ is involved in other recreational activities [20]. The latest comparative analysis of 15 European Union Member States revealed that $53.4 \%$ of Polish adults claim to do physical exercise on everyday basis [21]. It is probable that observed heterogeneity of the above data results from different methodology including various socio-economic groups of participants, different domains of measured PA as well as different PA assessment techniques. Although methodological discrepancies between the studies make precise comparisons impossible, observation of lifestyle trends in other countries (especially post communist societies) is of high importance. The report of Sigmundová et al. (2011) performed among 1653 respondents, who were randomly selected from across 8 Czech towns, revealed that about $51 \%$ of the participants were sufficiently active (including $27 \%$ of highly active individuals) [22]. A sedentary lifestyle was found among 4\%, while approximately $16 \%$ of the participants were little active. More importantly, meeting the PA health guidelines was assessed objectively by using pedometers. Accumulating 10000 steps per day was a criterion for a satisfactory PA level [22]. Another survey, published by Nédó and Paulik (2012), shows that self-reported physical inactivity (defined as exercise less than several times per week) was prevalent among $32.0 \%$ of Hungarians and $73.2 \%$ of Romanians [23]. Using the above definition, physical inactivity in our study population could be similar to that observed in Hungary (29.9\% of women and $26.7 \%$ of men). The results obtained in the NATPOL 2011 study show that PA level is associated with some socio-demographic and work-related factors. The women declared lower occupational and higher commuting activity in comparison with the men, which is in line with several previous reports $[13,14,16]$. Contrary to the results obtained in other studies conducted in Poland, we have not noted 
substantial differences between genders in distribution of LTPA frequency. The prevalence of women with low LTPA was found markedly lower in comparison with the national analyses performed over the years 2003$2005[13,14]$. Probably the results of the next edition of the WOBASZ Study (which has already started) will show if this is a stable trend.

Age appeared to be a potential factor influencing the likelihood of low LTPA, mainly in men. Polish seniors should become a priority group for public health messages as a sedentary lifestyle increases the risk of disability and progressive reduction in cardiopulmonary capacity and muscular strength [24].

As expected, hard physical work was related to a higher probability of low LTPA in women. In the previous studies conducted in Poland, high occupational activity was the main reason for sedentary behaviours during the leisure time [13]. However, in this analysis work-related PA have not appeared an important factor influencing LTPA among men.

Quite surprisingly, no significant correlations were found between educational level and LTPA. Although in crude analysis secondary and university education was strongly associated with a lower prevalence of a sedentary lifestyle, the multivariate model showed a trend for decreasing probability of low LTPA among higher educated individuals, but without statistical significance. This finding is in contrast to the previous studies which revealed a strong negative correlation between educational level and the prevalence of physical inactivity $[12,13,16]$. Increasing awareness of the significance of PA also among the least educated groups due to a more pronounced promotion of an active lifestyle in various socio-demographic groups in the last decade may constitute a probable explanation of these results [25].

Several limitations of the study should be acknowledged. The cross-sectional design of the study precludes the assumption of causality between the analyzed variables.
Moreover, PA was self-reported which could result in over-reporting of the amount of physical activity. The approach to PA assessment was mostly qualitative without information regarding intensity of exercise, time spent sitting, and kinds of activity at work. As a consequence, we were not able to assess the prevalence of "satisfactory" PA level according to the current guidelines. We are also aware of the fact that objective methods of PA assessment (accelerometers, pedometers, heart rate monitoring) are more precise than subjective measurements using questionnaires. However, due to the relative feasibility and cost constraints, PA assessment in large epidemiological studies in the countries with a middle-income level is usually based on questionnaires [26].

The strengths of our study include its national, randomized, and population-based design. Inclusion of both genders across a wide range of socio-demographic characteristics is also among important advantages of our study. As compared to the previous epidemiological studies in Poland, including new questions connected with commuting activity in this study can be perceived as a certain improvement in PA assessment. Asking about time spent walking to public transport (buses, trains, trams) may substantially diminish the prevalence of non-active commuters. Besser and Dannenberg observed that Americans who use transit spend on average 19 min daily walking to public transport and $29 \%$ of them achieve the recommended level of PA solely by this kind of activity [27].

According to the latest calculations, PA has a vast potential to improve health. If a sedentary lifestyle was decreased by $10 \%$ or $25 \%$, more than 533000 and more than 1.3 million deaths, respectively, could be averted every year worldwide [2]. Although experts recommend performing at least $30 \mathrm{~min}$ sessions of exercise, even a short workout session, between 10 and $20 \mathrm{~min}$, can be beneficial for health and can make achieving the guidelines possible $[17,28,29]$. Another crucial point is that while individuals 
should be motivated to adopt PA, public health priority should be to ensure safe and supportive environments. Creation of friendly environments can be associated with enhancing people's active lifestyle and meeting the PA health criteria $[22,30]$.

In summary, PA level of Polish adults seems to have improved, especially in terms of LTPA as compared with the results of the previous national reports. However, there is still an important percentage of those who are not involved in any kind of regular activity or do it very seldom. Regarding commuting activity as a potential contributor to overall PA, promoting this kind of PA seems particularly enhancing in the context of achieving health guidelines. Further studies concerning monitoring PA level and its determinants in Poland are crucial in order to elaborate more effective public health strategies.

\section{REFERENCES}

1. Morris JN, Heady JA, Raffle PAB, Roberts CG, Parks JW. Coronary heart disease and physical activity of work. Lancet. 1953;262(6795):1053-7, http://dx.doi.org/10.1016/S01406736(53)90665-5.

2. Lee IM, Shiroma EJ, Lobelo F, Puska P, Blair SN, Katzmarzyk PT. Effect of physical inactivity on major non-communicable diseases worldwide: An analysis of burden of disease and life expectancy. Lancet. 2012;380(9838):219-29, http://dx.doi. org/10.1016/S0140-6736(12)61031-9.

3. Khan KM, Thompson AM, Blair SN, Sallis JF, Powell KE, Bull FC, et al. Sport and exercise as contributors to the health of nations. Lancet. 2012;380(9836):59-64, http://dx.doi.org/ 10.1016/S0140-6736(12)60865-4.

4. Drygas W. [Is sedentary lifestyle still dangerous for health of Polish society?]. Med Sport. 2006;2(6)22:118-6. Polish.

5. Lee IM, Paffenberger RS. Associations of light, moderate, and vigorous physical activity with longevity. The Harvard Alumni Health Study. Am J Epidemiol. 2000;151(3):293-9, http://dx.doi.org/10.1093/oxfordjournals.aje.a010205.
6. Sesso HD, Paffenberger RS, Lee IM. Physical activity and coronary heart disease in men. The Harvard Alumni Health Study. Circulation. 2000;102:975-80, http://dx.doi. org/10.1161/01.CIR.102.9.975.

7. Kwaśniewska M, Kaczmarczyk-Chałas K, Pikala M, Broda G, Kozakiewicz K, Pająk A, et al. Commuting physical activity and prevalence of metabolic disorders in Poland. Prev Med. 2010;51(6):482-7, http://dx.doi.org/10.1016/ j.ypmed.2010.09.003.

8. Kwaśniewska M, Pikala M, Kaczmarczyk-Chałas K, Piwońska A, Tykarski A, Kozakiewicz K, et al. Smoking status, the menopausal transition, and metabolic syndrome in women. Menopause. 2012;19(2):194-201, http://dx.doi. org/10.1097/gme.0b013e3182273035.

9. Kwaśniewska M, Kaczmarczyk-Chałas K, Pikala M, Broda, Kozakiewicz K, Pająk A, et al. Socio-demographic and lifestyle correlates of commuting activity in Poland. Prev Med. 2010;50(5-6):257-61, http://dx.doi.org/10.1016/ j.ypmed.2010.02.011.

10. Bandosz P, O’Flaherty M, Drygas W, Rutkowski M, Koziarek J, Wyrzykowski B, et al. Decline in mortality from coronary heart disease in Poland after socioeconomic transformation: modelling study. BMJ. 2012;344:d8136, http:// dx.doi.org/10.1136/bmj.d8136.

11. Sjöström M, Oja P, Hagströmer M, Smith BJ, Bauman A. Health-enhancing physical activity across European Union countries: The Eurobarometer study. J Public Health. 2006;14:291-300, http://dx.doi.org/10.1007/s10389006-0031-y.

12. Varo JJ, Martinez-Gonzáles MA, de Irala-Estévez J, Kearney J, Gibney M, Martínez JA. Distribution and determinants of sedentary lifestyles in the European Union. Int J Epidemiol. 2003;32:138-46, http://dx.doi.org/10.1093/ije/dyg116.

13. Drygas W, Kwaśniewska M, Kaleta D, Pikala M, Bielecki W, Głuszek J, et al. Epidemiology of physical inactivity in Poland: prevalence and determinants in a former communist country in socioeconomic transition. Public Health. 2009;123(9): 592-7, http://dx.doi.org/10.1016/j.puhe.2009.08.004. 
14. Drygas W, Kwaśniewska M, Szcześniewska D, Kozakiewicz K, Głuszek J, Wiercińska E, et al. [Assessment of physical activity level among adult population of Poland. Results of the WOBASZ Project]. Kardiol Pol. 2005;63:636-40. Polish.

15. Zdrojewski T, Rutkowski M, Bandosz P, Gaciong Z, Jędrzejczyk T, Solnica B, et al. Prevalence and control of cardiovascular risk factors in Poland. Assumptions and objectives of the NATPOL 2011 Survey. Kardiol Pol. 2013;71(4):38192, http://dx.doi.org/10.5603/KP.2013.0066.

16. Drygas W, Skiba A, Bielecki W, Puska P. [Physical activity level of the participants of the "Bridging East-West Health Gap" Project]. Med Sport. 2001;(Suppl 2):119-28. Polish.

17. Physical Activity Guidelines Advisory Committee. Physical Activity Guidelines Advisory Committee Report, 2008. Washington, DC: US Department of Health and Human Services, 2008.

18. Zdrojewski T, Bandosz P, Szpakowski P, et al. [Prevalence of the main risk factors of cardiovascular diseases in Poland. Results of the NATPOL Plus Study]. Kardiol Pol. 2004;61(Suppl 4):1-25. Polish

19. European Health Interview Survey (EHIS). EUROSTAT; 2011 [cited 2012 Apr 10]. Available from http:// epp.eurostat.ec.europa.eu/cache/ITY_SDDS/en/hlth_ehis_ esms.htm.

20. Abu-Omar K, Rütten A. Relation of leisure time, occupational, domestic, and commuting physical activity to health indicators in Europe. Prev Med. 2008;47(3):319-23, http:// dx.doi.org/10.1016/j.ypmed.2008.03.012.

21. Piątkowska M. Self-rated physical activity level across Europe - Poland and other European countries. Biol Sport. 2012;29(1):23-31, http://dx.doi. org/10.5604/20831862.979848.

22. Sigmundová D, El Ansari W, Sigmund E. Neighbourhood environment correlates of physical activity: a study of eight Czech regional towns. Int J Environ Res Public Health. 2011;8(2):341-57, http://dx.doi.org/10.3390/ ijerph8020341.
23. Nédó E, Paulik E. Association of smoking, physical activity, and dietary habits with socioeconomic variables: A crosssectional study in adults on both sides of the HungarianRomanian border. BMC Public Health. 2012;12:60, http:// dx.doi.org/10.1186/1471-2458-12-60.

24. Lacour JR, Kostka T, Bonnefoy M. Physical activity to delay the effects of aging on mobility. Presse Med. 2002;31: 1185-92.

25. Ruszkowska-Majzel J, Drygas W. [The Great Nationwide Physical Activity Campaign "Revitalize Your Heart" as an effective method to promote active lifestyle in Poland]. Przegl Lek. 2005;62, Suppl 3:23-6. Polish.

26. Lipert A, Jegier A. [Methods of measurement of physical activity]. Med Sport. 2009;3:155-68. Polish.

27. Besser LM, Dannenberg AL. Walking to public transit: steps to help meet physical activity recommendations. Am J Prev Med. 2005;29(4):273-80.

28. Perk J, De Backer G, Gohlke H, Graham I, Reiner Z, Verschuren M, et al. European Guidelines on cardiovascular disease prevention in clinical practice. The Fifth Joint Task Force of the European Society of Cardiology and Other Societies on Cardiovascular Disease Prevention in Clinical Practice (constituted by representatives of nine societies and by invited experts). Developed with the special contribution of the European Association for Cardiovascular Prevention \& Rehabilitation (EACPR). Eur Heart J. 2012;33(13):1635-701, http://dx.doi.org/10.1093/ eurheartj/ehs092.

29. Drygas W, Jegier A, Kostka T, Dziankowska-Zaborszczyk E, Kozińska J, Kwaśniewska M. Long-term effects of different physical activity levels on cardiovascular risk: results of prospective 17-year follow-up study of middle-aged men. Sports Med. 2012;3(4):179-287.

30. Heath GW, Parra DC, Sarmiento OL, Andersen LB, Owen N, Goenka S, et al. Evidence-based intervention in physical activity: lessons from around the world. Lancet Physical Activity Series Working Group. Lancet. 2012;380:272-81, http:// dx.doi.org/10.1016/S0140-6736(12)60816-2 .

This work is available in Open Access model and licensed under a Creative Commons Attribution-NonCommercial 3.0 Poland License - http://creativecommons.org/ licenses/by-nc/3.0/pl/deed.en. 